\title{
The Variation Law of Longitudinal Sonic Wave Velocity in Argillaceous Rock in Kohala Hydropower Project in Pakistan
}

Dong Cheng Shan ${ }^{1,}$, Yuan Yan Chao ${ }^{1, b}$, Hu Jian Feng ${ }^{1, c}$ and Yang Zheng Quan $^{2, d}$

${ }^{1}$ China Water Resources Beifang Investigation, Design and Research Co. Ltd, No.60, Dongting Road, Hexi District, Tianjin, P. R. China (300222)

${ }^{2}$ Department of Geotechnical Engineering, IWHR, No.20, West Chegongzhuang Road, Haidian District, Beijing, P.R. China (100048)

aspikedong@qq.com, b283914255@qq.com, ${ }^{c 760430901 @ q q . c o m, ~ d 28508030 @ q q . c o m ~}$

Keywords: Kohala Hydropower Project, Argillaceous rock, Variation law, Longitudinal sonic wave velocity

\begin{abstract}
During the investigation in powerhouse area in Kohala hydropower project, slaking is found in most of the argillaceous rock, whose integrity decreasing with time, and cause the rock strength decreases. During investigation, we performed longitudinal sonic wave velocity test, therefore the variation law is preliminarily confirmed, which could be used as a guide for the supporting of excavation parts in argillaceous rock during construction.
\end{abstract}

\section{Introduction}

The argillaceous rock at powerhouse area in Kohala hydropower project in Pakistan mainly consists of argillaceous siltstone, silty mudstone and mudstone, which takes the dominant proportion at powerhouse area, since it's the control lithology with relatively low strength, the engineering geological properties at powerhouse area mainly is determined by argillaceous rock. Since the slaking of argillaceous rock will worsen the rock integrity and reduce its strength, the surrounding rock stability of underground powerhouse will be directly affected by whether being supported or not during excavation. In this study, the variation law of longitudinal sonic wave velocity with time in different kinds of argillaceous rock is preliminarily determined, upon which the initial supporting time after excavation is suggested, so that the doubt on initial supporting time during construction could be answered, and hopefully the result will be helpful for other projects with similar lithology.

\section{General Geology}

The planned Kohala hydropower project is located in Kashmir in Pakistan, with bedrock of powerhouse area consists of Murree formation of early Miocene series in Tertiary, among which the argillaceous rock mainly includes: 
Sh: (Mudstone/Laminated argillaceous siltstone and silty mudstone). This rock unit is also less exposed within the powerhouse area. It is reddish brown in colour, argillaceous textured with chlorite in places, comparatively less hard than the other rock types, thickly to moderately bedded at fresh state, locally laminated in appearance as shale due to tectonic activities.

During the investigation, core samples of argillaceous rock slaked and cracked after being taken out of borehole shortly, which caused the integrity and strength decreased severely. (See Pic. 1)

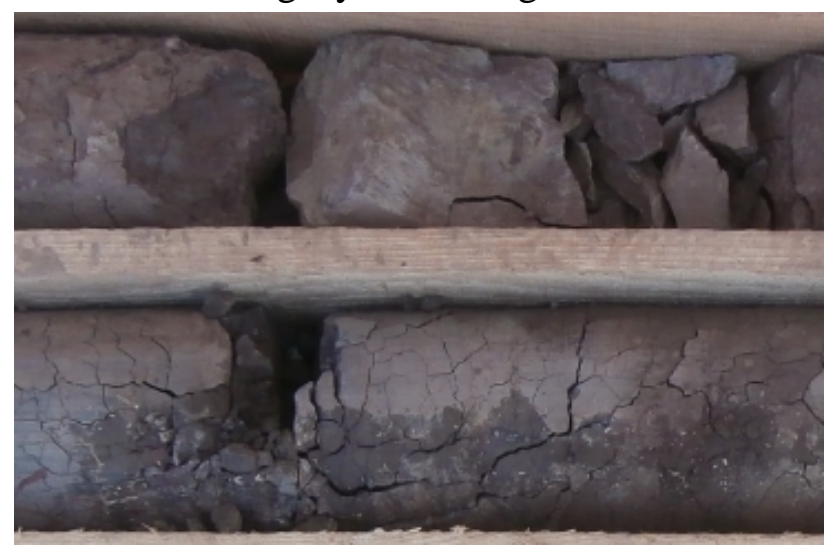

Pic. 1 The disintegration of argillaceous rock

\section{Variation of longitudinal sonic wave velocity with time}

The geophysical test is more practical than rock strength test, and the law determined could meet the working requirement $[1,2]$.

In order to know the variation with time of the longitudinal sonic wave velocity [3], 17 core samples of different rock types (mudstone, silty mudstone and argillaceous siltstone) were taken from borehole ZKC14 and ZKC15 drilled at the powerhouse area. The first test for each and every samples were performed immediately after its removal from the borehole and test interval varied in the range of 1 24 hours. The statistical analysis of test results indicates that there are two main variations in the pattern, which are the descending type and the ascending-descending type. Test results of different rock types are descripted as following:

\section{(1) Mudstone}

The variation curves of both samples are of the descending type (See Fig. 1), and the original sonic velocities are $2210 \mathrm{~m} / \mathrm{s}$ and $2570 \mathrm{~m} / \mathrm{s}$ respectively. The sonic velocity decreases sharply with time within the first 22 hours, and the sonic velocity at 8 hours is $2050 \mathrm{~m} / \mathrm{s}$ and $2290 \mathrm{~m} / \mathrm{s}$ respectively. The decreasing rate of the sonic velocity compared with the original velocity is $7.2 \%$ and $10.9 \%$, averaged $9.1 \%$; at the end of 22 hours, the sonic velocities are $1280 \mathrm{~m} / \mathrm{s}$ and $1790 \mathrm{~m} / \mathrm{s}$, with a decreasing rate of $42.1 \%$ and $30.4 \%$, averaged $36.3 \%$; from 22 hours onward, the velocity curve varies gently and is almost stable (sonic velocity varies from $1200 \mathrm{~m} / \mathrm{s}$ to $1600 \mathrm{~m} / \mathrm{s}$ ). 


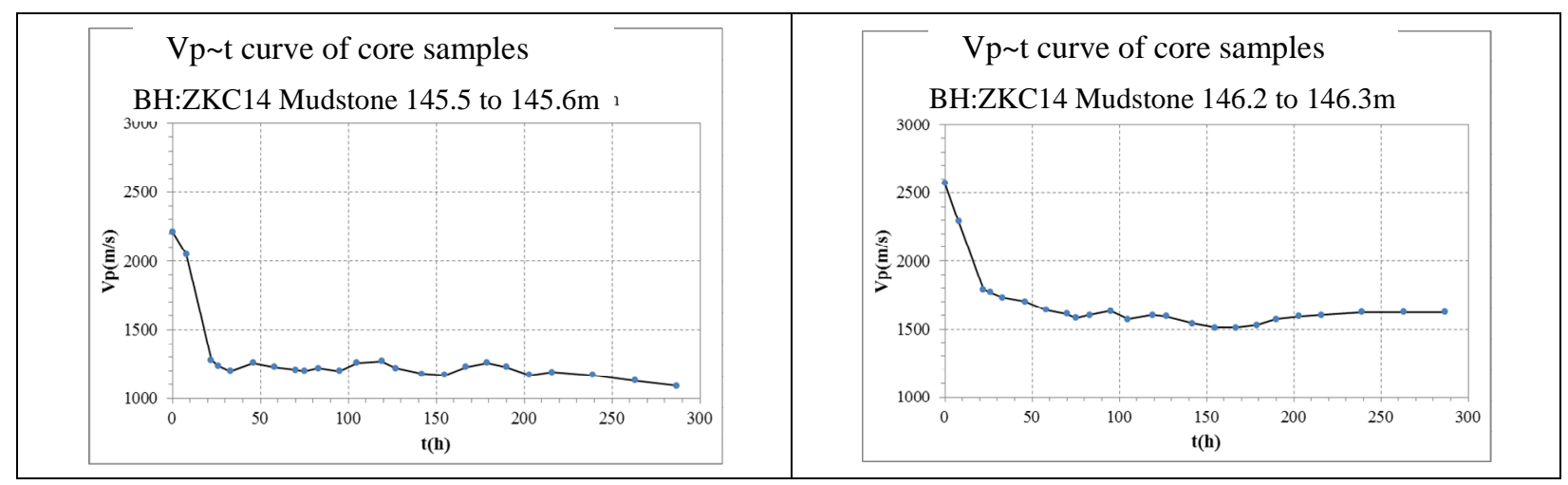

Fig. $1 \quad$ Vp t curve of mudstone (Descending type)

\section{(2) Silty mudstone}

The variation curves of both samples are the ascending-descending type (See Fig. 2), and the original wave velocities are $2950 \mathrm{~m} / \mathrm{s}$ and $3080 \mathrm{~m} / \mathrm{s}$ respectively, averaged at $2985 \mathrm{~m} / \mathrm{s}$. Wave velocity increases with time to peak values of $3090 \mathrm{~m} / \mathrm{s}$ and $3340 \mathrm{~m} / \mathrm{s}$ after 16 to 25 hours and the rate of increase is $4.7 \%$ and $8.4 \%$ respectively, averaged $6.6 \%$. Following this, the wave velocity decreases sharply during 30 to 47 hours; after 47 hours the sonic velocity decreases gradually and reaches a stable condition after 166 to 196 hours, with sonic velocities of $2720 \mathrm{~m} / \mathrm{s}$ and $2530 \mathrm{~m} / \mathrm{s}$, averaged $2625 \mathrm{~m} / \mathrm{s}$, which descends at a rate of $7.8 \%$ and $17.9 \%$, averaged $12.1 \%$ compared with the original condition.

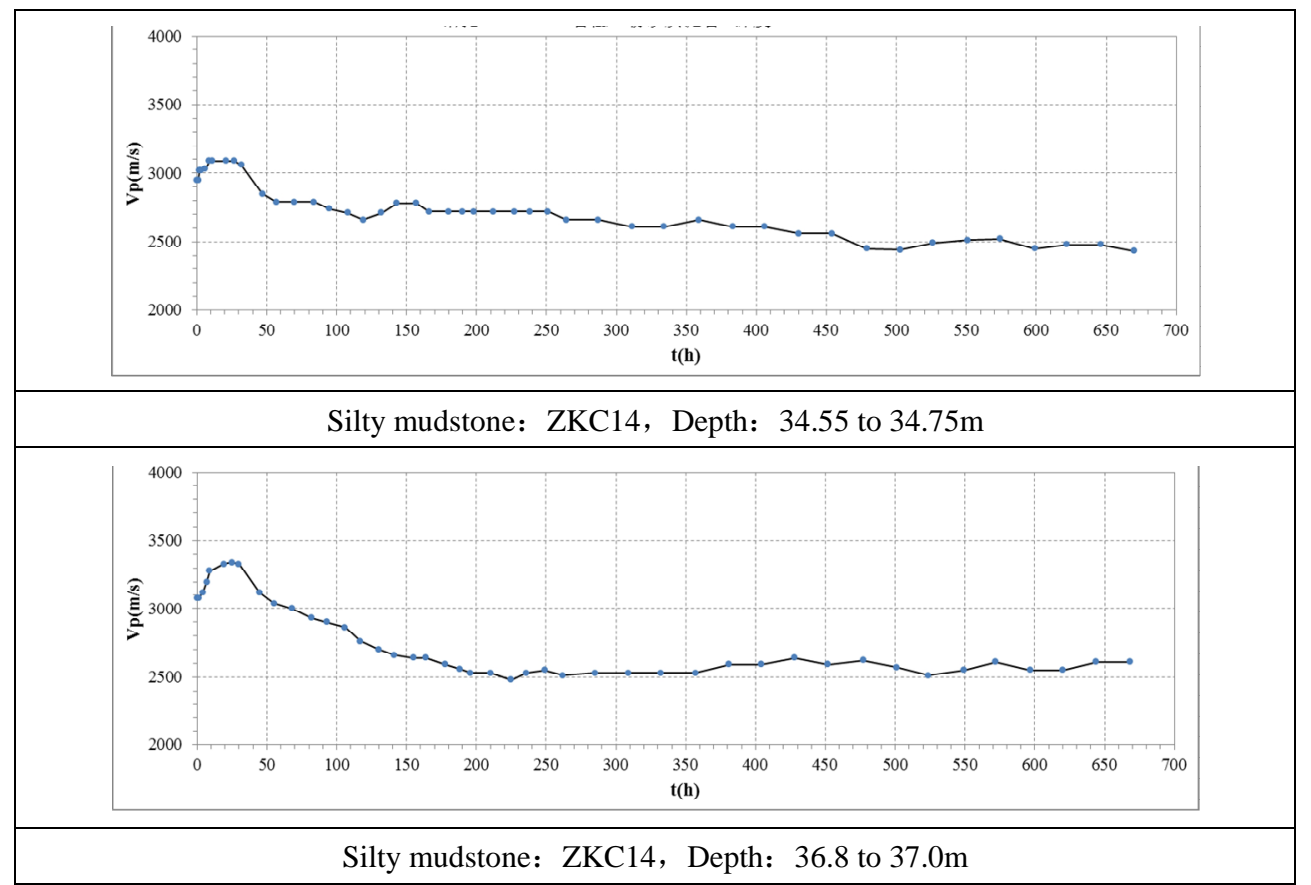

Fig. 2 Vp t curve of silty mudstone (ascending-descending type)

\section{(3) Argillaceous siltstone}

13 samples were tested among which 7 results were of the descending type (see Fig. 3) and the remaining 6 results were of the ascending-descending type (see Fig. 4). In general, the measured original longitudinal wave velocity varies in the range of 2240 to $3960 \mathrm{~m} / \mathrm{s}$, averaged $3270 \mathrm{~m} / \mathrm{s}$; while the stable longitudinal wave velocity varies from 1140 to $3870 \mathrm{~m} / \mathrm{s}$, averaged $2920 \mathrm{~m} / \mathrm{s}$. The 
time until it reaches a stable condition varies in the range of 24 to 164 hours and is averaged 63 hours. The sonic velocity decreases by 2.3 to $49.1 \%$ (averaged $11.9 \%$ ) compared to the original condition. Additionally, among the 7 samples of descending-type, the original longitudinal wave velocity varies in the range of 2240 to $3890 \mathrm{~m} / \mathrm{s}$, averaged $3370 \mathrm{~m} / \mathrm{s}$; whilst the stable wave velocity of 1140 to $3560 \mathrm{~m} / \mathrm{s}$, averaged $2890 \mathrm{~m} / \mathrm{s}$, and the time taken before a stable condition reached varies in the range of between 24 to 48 hours, averaged 37 hours. The longitudinal wave velocity decreases by 5.7 to $49.1 \%$ (averaged $16.0 \%$ ) compared to the original condition; whilst among the 6 samples of the ascending-descending type, the original longitudinal wave velocity varies in the range of between 2540 to $3960 \mathrm{~m} / \mathrm{s}$, averaged $3160 \mathrm{~m} / \mathrm{s}$ and reaches the peak value, which varies from $2790 \mathrm{~m} / \mathrm{s}$ to $4330 \mathrm{~m} / \mathrm{s}$, (averaged $3400 \mathrm{~m} / \mathrm{s}$ ) and increases by 1.0 to $13.6 \%$ (averaged $8.2 \%$ ) compared to the original condition; Then the wave velocity starts decreasing and reaching a stable condition after 36 to 164 hours (averaged 93 hours). The wave velocity of the stable condition varies in the range of 2100 to $3870 \mathrm{~m} / \mathrm{s}$, averaged $2950 \mathrm{~m} / \mathrm{s}$, which decrease by $2.3 \%$ to $17.3 \%$ (averaged $7.1 \%$ ) compared to the original condition.

However, the above-mentioned variations in the longitudinal wave velocity within the rock mass are also affected by the sampling method and the disturbed degree of the samples.

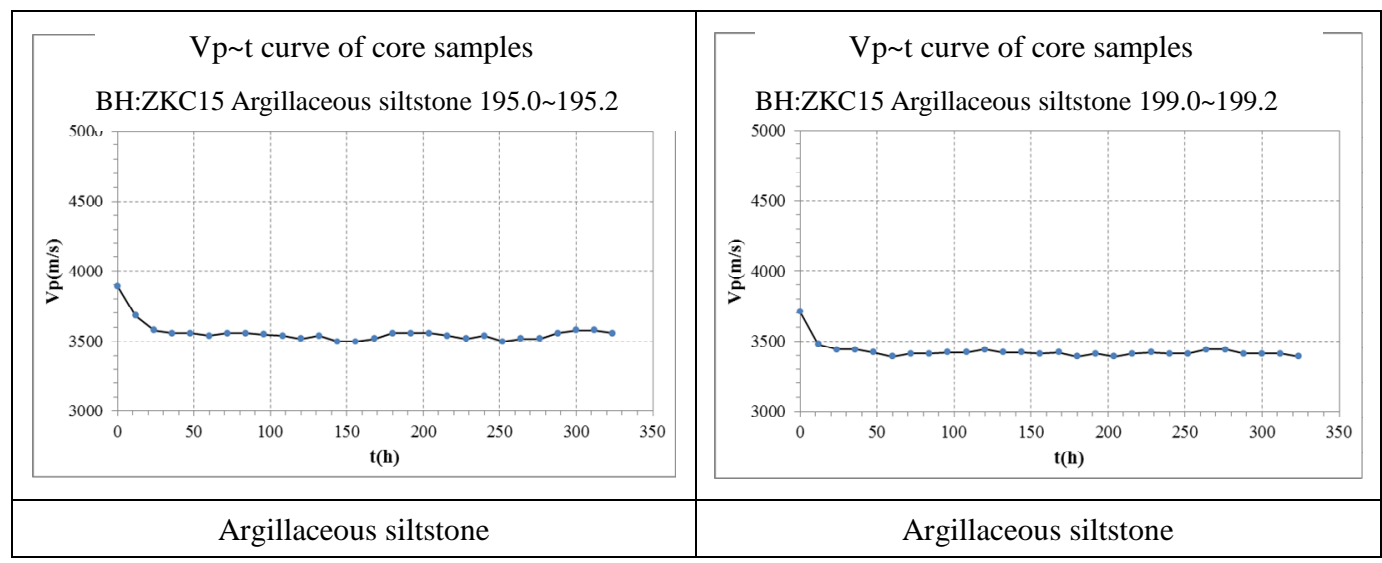

Fig. 3 Vp t curve of argillaceous siltstone (descending type)

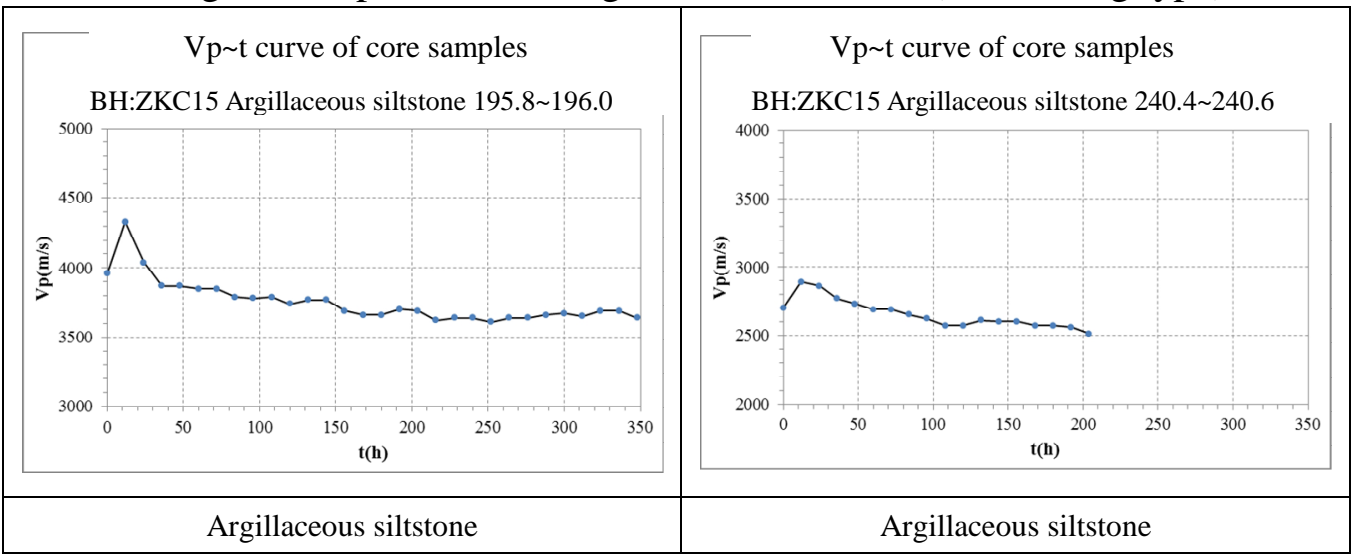

Fig. $4 \quad V p \sim t$ curve of argillaceous siltstone (ascending-descending type) 


\section{Conclusion}

According to the research result, the longitudinal sonic wave velocity in argillaceous rock will decrease eventually, among which the condition in mudstone is the fastest, shows the integrity change of argillaceous rock with time. In order to avoid this disadvantage, a protection layer shall be kept before reaching the final excavation position during construction. It shall be sealed off in time after final excavation, meanwhile anti-seepage and drainage measures shall be taken duly. The initial supporting shall be conducted within 8 hours in mudstone, and it is suggested that in the rest argillaceous rock, such as silty mudstone and argillaceous siltstone shall be conducted within 24 hours, meanwhile the supporting shall be flexible supporting, which could keep the integrity of the surrounding rock.

\section{Acknowledgements}

This work was financially supported by the National Natural Science Foundation of China (Grant No. 51509272), the special scientific research foundation of China Institute of Water Resources and Hydropower Research (GE0145B292017), the Public Service Sector R\&D Project of Ministry of Water Resource of China (Grant No. 201501035).

\section{References}

[1] Manual of Engineering Geology (4th Edition) [M]. Beijing: China water resource and hydro-powder publishing house, 2007. (in Chinese)

[2] Handbook of Hydropower Engineering Geology [M]. Beijing: China water resource and hydro-powder publishing house, 2011. (in Chinese)

[3] Ministry of Water Resources of the People's Republic of China. Code for engineering geophysical exploration of water resources and hydropower (SL 326-2005) [S] Beijing: 2005. (in Chinese) 